\title{
Efficacy of Topical Propranolol gel in Infantile Hemangioma
}

\author{
Malumani Malan' ${ }^{1}$ Wu Jianbo ${ }^{2}$ and Song Ji Quan ${ }^{3 *}$ \\ ${ }^{1}$ Department of Dermatology and Venereology, Zhongnan Hospital of Wuhan University, China \\ ${ }^{2}$ Deputy Head of Department of Dermatology and Venereology, Zhongnan Hospital of Wuhan University, China \\ ${ }^{3}$ Head of Department of Dermatology and Venereology, Zhongnan Hospital of Wuhan University, China
}

Submission: October 06, 2018; Published: November 30, 2018

*Corresponding author: Song Ji Quan, Head of Department of Dermatology and Venereology, Zhongnan Hospital of Wuhan University, China

\begin{abstract}
Infantile hemangiomas (IHs) are vascular neoplasms characterized by aberrant proliferation of endothelial cells and abnormal blood vessel architecture, characterized by an initial phase of rapid proliferation followed by an involutional phase. They are the commonest benign neoplasms of infancy. We discuss a cases report of a 7-month old male infant who responded well to topical propranolol gel-ointment which offers a nouvelle, effective and acceptable means of treating Infantile Hemangiomas. Propranolol gel is efficacious in treating IH, with also a low side effects profile or none at all. This case report offers clinicians a quick review and acceptable alternative approach in management of IH.
\end{abstract}

Keywords: Infantile hemangiomas, Strawberry hemangiomas, Infantile capillary hemangiomas, propranolol gel/ointment, Beta-blocker

Abbreviation: IH: Infantile Hemangioma; GLUT1: Glucose Transporter-1

\section{Introduction}

Infantile hemangiomas (IHs) are vascular neoplasms characterized by aberrant proliferation of endothelial cells and abnormal blood vessel architecture, characterized by an initial phase of rapid proliferation followed by an involutional phase $[1,2]$. They are also referred as infantile capillary hemangiomas, [3] strawberry hemangiomas.

HI usually appears in the initial weeks of life and grows most rapidly over the first six months. Usually, growth is complete, and involution has commenced by twelve months [4]. Subhash et al notes that half of all infantile hemangiomas would have completed involution by age five years, $70 \%$ by age seven, and most of the remainder by age twelve years.

They are the commonest benign neoplasms of infancy. According to Darrow et al., the incidence of IH is estimated at approximately $5 \%$ of infants and has a female to male predominance ratio ranges from 1.4:1 to 3:1 [1]. Some attributable risk factors for $\mathrm{IH}$ include the following but not limited to white race, prematurity, low birth weight, multiple gestation pregnancy, placenta previa, advanced maternal age, and preeclampsia. Other risk factors may include in utero diagnostic procedures like chorionic villus sampling and amniocentesis, use of fertility drugs or erythropoietin, breech presentation, and being first born [5].
Although most of these neoplasms are small and harmless, [6] some may be life- or function-threatening or have associated structural congenital anomalies [7]. Early lesions may resemble a red scratch or patch, a white patch, or a bruise. Clinically, the majority of hemangiomas occur on the head and neck, but they can occur almost anywhere [8]. The appearance and color of the hemangioma depends on its location and depth within the level of the skin, thus categorized as either superficial or deep infantile hemangioma.

Although the pathogenesis of hemangiomas is not well understood, epidemiological findings and advances in the knowledge of angiogenesis have provided some clues, such as the theory of placental origin, the specific marker glucose transporter 1 and the activation of angiogenesis factor angiopoietin-2. This has become an acceptable unifying theory.

Histological presentation collarets to the clinical phases; proliferative IHs reveal well-defined masses of capillaries lined by plump endothelial cells, arranged in lobules, they are often described as having enlarged draining veins. Involuting phase of IHs reveals, fibrofatty stroma, residual "ghost" vessels, mast cells, and apoptotic bodies [9].

Immunohistochemical staining of IH is positive for glucose transporter 1 (GLUT1), CD34, CD31, factor VIII-related antigen, 
and others. Huang et al notes that GLUT1 is the most useful and widely used marker for the diagnosis of hemangiomas $[1,10]$.

In this case report, we discuss the role of topical propranolol in the treatment of an innocuous infantile hemangioma.

\section{Case History}

A healthy looking 7-months old male infant presents to the Dermatology outpatient of Zhongnan Hospital of Wuhan University with an history of an increasing skin lesion on the back since birth, with gradual increase in size. He had no any other complaints. His Birth and developmental history were unremarkable and had no significant past medical nor family history. The physical examination revealed strawberry like lesions on the left lateralposterior aspect of body about less than $1 \%$ of body surface area and appeared purplish-red lobulated like macules which were spongy in consistency and non-tender as shown on Figure 1. No any other investigation was done.

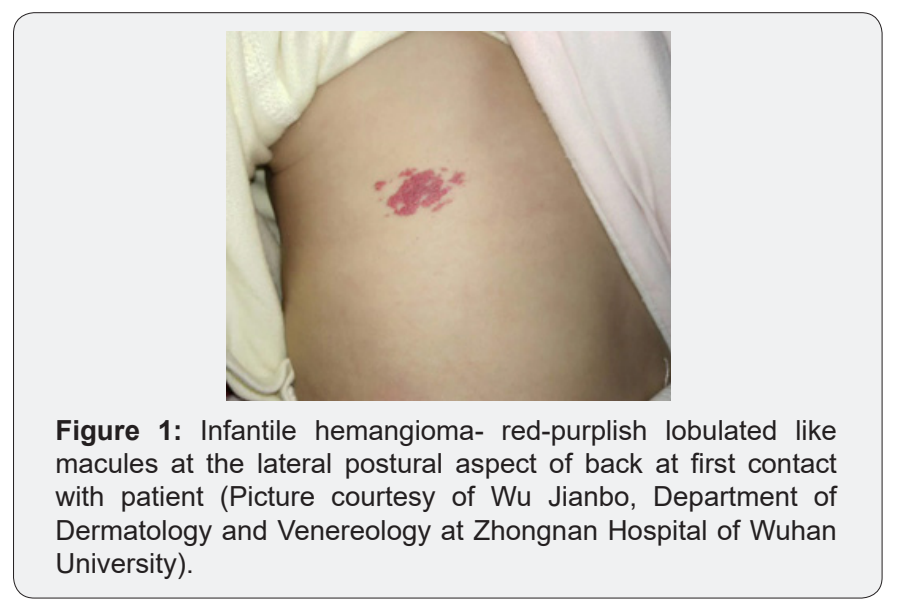

A clinical diagnosis of infantile Hemangioma was made, and patient was started on a cocktail of Propranolol 150mg in $14 \mathrm{~g}$ mucopolysaccharide polysulfide cream, daily application nocte. It showed significant resolution after one month of application Figure 2. There was complete resolution at 3 -months as seen in Figure 3.



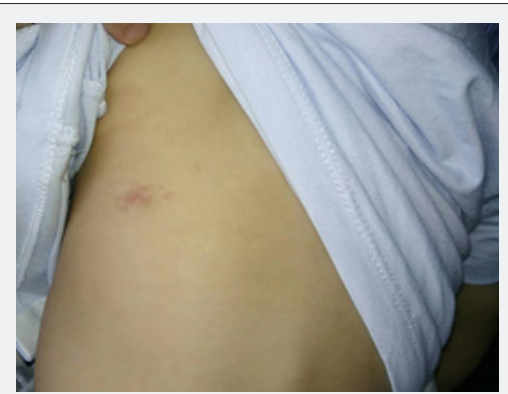

Figure 3: Infantile hemangioma-after three months of treatment on topical propranolol. (Picture courtesy of Wu Jianbo, Department of Dermatology and Venereology at Zhongnan Hospital of Wuhan University).

There were no local or systemic side effects observed with the use of topical propranolol gel -ointment.

\section{Discussion}

Most guardians with children with these benign neoplasms are increasingly seeking medical attention for innocuous conditions like infantile hemangioma. Our patient had a harmless strawberry hemangioma on the lateral posterior aspect of the back. Although the lesion was painless, the psychological stress on the guardians in view of cosmetic appearance of their child demanded action.

The infant was started on a cocktail ointment gel of Propranolol 150mg in 14g mucopolysaccharide polysulfide cream, daily application nocte. This application of topical propranolol was administered by the guardians as an out-patient bases. This formulation showed significant response and without any noticeable local or systemic side effects in one month of starting treatment and complete resolution of the lesion in three months as shown in Figures 2 \& 3 respectively.

The role of systemic use of propranolol is now being advocated by many physicians in the management of IH $[11,12]$. Propranolol has been associated with less severe side effects [13] in comparison to systemic corticosteroids. However, topical propranolol may become a better option for treatment of uncomplicated IH which require 'active non-intervention', a term that is slowly replacing the term benign neglect. The use of topical propranolol is gaining ground due to its favorable pharmacokinetics and dynamics [14].

Despite the knowledge that there is gradual involution of IH over the next 5-7 years. Fading of lesion usually heralds regression of the hemangioma, but involution remains unpredictable, [9] thus the need for active intervention is advised.

By recognizing that not all hemangiomas are the same, physicians and parents can make informed choices regarding the possible interventions.

The major goals of management include:

1) Preventing or reversing life- or function-threatening complications

2) Preventing permanent disfigurement 
3) Treating ulcerations

4) Minimizing psychosocial distress to the patients and their families and

5) Avoiding overly aggressive, potentially scarring procedures for lesions that have a strong probability of involuting without significant residua.

For our patient the main reason for treatment was minimizing psychosocial distress to the guardians, possible complications like ulcerations which is associated with IH and avoiding potentially scaring procedures like laser therapy. Thus, one other advantage of topical propranolol over surgical methods is having less significant residua.

In addition, the use of topical propranolol offers clinicians an effective, alternative and acceptable route of management of IH. It can be used as an adjuvant therapy in selected cases as deemed fit by clinician. Bota et al. notes that if a clinician does not observe any appreciate response with four weeks on topical propranolol(betablocker), then it is a case of non-response to propranolol [15].

\section{Conclusion}

Topical propranolol gel-ointment offers (topical beta blockers) [15] a nouvelle, effective and acceptable means of treating Infantile Hemangiomas. It has shown that it is efficacious with also mild side effects or none at all $[16,17]$. It is affordable, safer and can be used as an out-patient basis with fairly well spaced review intervals.

\section{References}

1. Darrow DH, Greene AK, Mancini AJ, Nopper AJ (2015) Diagnosis and Management of Infantile Hemangioma: Executive Summary. Pediatrics 136(4): 786-791.

2. Bruckner AL, Frieden IJ (2003) Hemangiomas of infancy. Jam Acad Dermatol 48(4): 477-493.

3. Léauté-Labrèze C, Taïeb A (2008) Efficacy of beta-blockers in infantile capillary haemangiomas: the physiopathological significance and therapeutic consequences. Ann Dermatol Venereol 135(12): 860-862.

4. Li J, Chen X, Zhao S, Hu X, Chen C, et al., (2011) Demographic and Clinical Characteristics and Risk Factors for Infantile Hemangioma: A Chinese Case-Control Study. Arch Dermatol 147(9): 1049-1056.

This work is licensed under Creative

Commons Attribution 4.0 Licens

DOI: 10.19080/AJPN.2018.07.555769
5. Rasul S (2013) Clinical Characteristics and Risk Factors for Infantile Hemangioma-A Case Control Study. Eur J Pediatr Surg 24(01): 102-112.

6. Ma X1, Zhao T, Xiao Y, Yu J, Chen H, et al., (2013) Preliminary experience on treatment of infantile hemangioma with low-dose propranolol in China. Eur J Pediatr 172(5): 653-659.

7. Kim HJ, Colombo M, Frieden IJ (2001) Ulcerated hemangiomas: Clinical characteristics and response to therapy. J Am Acad Dermatol 44(6): 962-972.

8. Drolet BA, Esterly NB, Frieden IJ (1999) Hemangiomas in Children. N Engl J Med 341(3): 173-181.

9. Ceisler EJ, Santos L, Blei F (2004) Periocular Hemangiomas: What Every Physician Should Know. Pediatr Dermatol 21(1): 1-9.

10. Huang L, Nakayama H, Klagsbrun M, Mulliken JB, Bischoff J (2015) Glucose transporter 1-positive endothelial cells in infantile hemangioma exhibit features of facultative stem cells. Stem Cells Dayt Ohio 33(1): 133-145.

11. Sagi L, Zvulunov A, Lapidoth M, Ben Amitai D (2014) Efficacy and safety of propranolol for the treatment of infantile hemangioma: a presentation of ninety-nine cases. Dermatol Basel Switz 228(2): 136144.

12. Zou HX, Jia J, Zhang WF, Sun ZJ, Zhao YF (2013) Propranolol inhibits endothelial progenitor cell homing: a possible treatment mechanism of infantile hemangioma. Cardiovasc Pathol Off J Soc Cardiovasc Pathol 22(3): 203-210.

13. Baselga E, Dembowska-Baginska B, Przewratil P, González-Enseñat MA, Wyrzykowski D, et al., (2018) Efficacy of Propranolol Between 6 and 12 Months of Age in High-Risk Infantile Hemangioma. Pediatrics142(3).

14. Yujuan T, Shaoquan C, Zaizhong Z, Shuming C, Guoliang H, et al., (2015) Effect of propranolol gel on plasma VEGF, bFGF and MMP-9 in proliferating infantile hemangiomas of superficial type. Chin J Plast Surg 31(4): 268-273.

15. Bota M, Popa G, Blag C, Tataruv A (2015) Infantile Hemangioma: A Brief Review. Clujul Med 88(1): 23-27.

16. Mashiah J, Kutz A, Rabia SH, Ilan EB, Goldberg I, et al., (2017) Assessment of the effectiveness of topical propranolol $4 \%$ gel for infantile hemangiomas. Int J Dermatol 56(2): 148-153.

17. Tang YJ, Zhang ZZ, Chen SQ, Chen SM, Li CJ, et al., (2015) Effect of topical propranolol gel on plasma renin, angiotensin II and vascular endothelial growth factor in superficial infantile hemangiomas. J Huazhong Univ Sci Technolog Med Sci 35(5): 759-762.

\section{Your next submission with Juniper Publishers} will reach you the below assets

- Quality Editorial service

- Swift Peer Review

- Reprints availability

- E-prints Service

- Manuscript Podcast for convenient understanding

- Global attainment for your research

- Manuscript accessibility in different formats

( Pdf, E-pub, Full Text, Audio)

- Unceasing customer service

\section{Track the below URL for one-step submission}

https://juniperpublishers.com/online-submission.php 